\title{
Cell fusion in cancer hallmarks: Current research status and future indications (Review)
}

\author{
HAO-FEI WANG ${ }^{*}$, WEI XIANG ${ }^{*}$, BING-ZHOU XUE, YI-HAO WANG, DONG-YE YI, \\ XIAO-BING JIANG, HONG-YANG ZHAO and PENG FU \\ Department of Neurosurgery, Union Hospital, Tongji Medical College, \\ Huazhong University of Science and Technology, Wuhan, Hubei 430022, P.R. China
}

Received December 5, 2020; Accepted April 9, 2021

DOI: $10.3892 / 01.2021 .12791$

\begin{abstract}
Cell fusion is involved in several physiological processes, such as reproduction, development and immunity. Although cell fusion in tumors was reported 130 years ago, it has recently attracted great interest, with recent progress in tumorigenesis research. However, the role of cell fusion in tumor progression remains unclear. The pattern of cell fusion and its role under physiological conditions are the basis for our understanding of the pathological role of cell fusion. However, the role of cell fusion in tumors and its functions are complicated. Cell fusion can directly increase tumor heterogeneity by forming polyploids or aneuploidies. Several studies have reported that cell fusion is associated with tumorigenesis, metastasis, recurrence, drug resistance and the formation of cancer stem cells. Given the diverse roles cell fusion plays in different tumor phenotypes, methods based on targeted cell fusion have been designed to treat tumors. Research on cell fusion in tumors may provide novel ideas for further treatment.
\end{abstract}

\section{Contents}

1. Introduction

2. Pattern of cell fusion

3. Cell fusion in physiological processes

4. Cell fusion in cancer hallmarks

5. Targeting cell fusion for tumor treatment

6. Conclusions

Correspondence to: Dr Peng Fu or Dr Wei Xiang, Department of Neurosurgery, Union Hospital, Tongji Medical College, Huazhong University of Science and Technology, 1277 Jiefang Avenue, Wuhan, Hubei 430022, PR China

E-mail:pfu@hust.edu.cn

E-mail: xiangwei20@hotmail.com

*Contributed equally

Key words: cell fusion, cancer therapy, hybrid cells, cell fusion in cancer, fusogens

\section{Introduction}

Cell fusion is a phenomenon that exists widely in the physiological and pathological conditions of organisms (1). Cell fusion involves two cells merging together through their plasma membranes, causing their cytoplasm to mix to form hybrids, obtaining new biological characteristics, functions and phenotypes (1). Some types of cells, such as gametes, myoblasts, macrophages and syncytiotrophoblasts, have the ability to form fused cells or polyploids, which are important for species passage, development and the maintenance of normal physiological functions (2). Recent studies have demonstrated that cell fusion can also occur in the occurrence and progression of some diseases, such as viral infections and tumors (3-5). The present review discusses the effects of cell fusion in malignant tumors and provides support and reference for tumor research and treatment. The present study discusses the phenomenon and mechanism of cell fusion in humans, and cell fusion events in the tumor microenvironment and their roles in tumor progression. In addition, potential cancer treatment options targeting cell fusion are considered.

\section{Pattern of cell fusion}

The pattern of cell fusion can be divided into three phases: i) Contact and dehydration, ii) hemifusion and iii) the formation and expansion of a fusion pore (3), all of which are energy consuming (6). Prefusion preparation is a prerequisite for cell fusion to accurately fuse specific cells (Fig. 1A) (7). Hernández and Podbilewicz (8) further divided the prefusion preparation process into three steps, differentiation, recognition and adhesion. The expression of specific recognition or adhesion-associated proteins during preparation is sufficient and necessary for cell fusion; however, this does not mean that they are directly involved in the fusion process itself; they just help specific cells maintain proximity $(8,9)$. In this process, the cells are close enough $(<10 \mathrm{~nm})$, and the distance gradually becomes $<1 \mathrm{~nm}$ under the activation of some proteins accompanied by the removal of water molecules between cells during dehydration (Fig. 1B) (10,11). At such a close distance, the plasma membrane begins to bend, and the outer layer of the phospholipid bilayer merges, which is also known as hemifusion (Fig. 1C) (12,13). Consequently, the inner layer further 
merges and forms a fusion pore between the cells (6) (Fig. 1D). As the fusion pores expand, the cytoplasm is completely mixed to form a hybrid containing the genomes and several organelles, such as mitochondria of the two parental cells (Fig. 1E) (14). The proteins that are activated during cytoplasmic membrane fusion that directly mediate and induce cell fusion are referred to as fusogens $(15,16)$. Fusogens assemble into unilateral or bilateral complexes, which determine the site of cell fusion and overcome the energy barriers that are required to prevent the anti-fusion mechanism (17). There are four families of fusogens that are explicitly involved in cell-cell fusion, of which only one is expressed in human cells, syncytins, which play a key role in the development of human placental syncytiotrophoblasts (8). Given that differentiated cells do not share the same molecular mechanism, there are studies on fusogens in different types of human cells (18-20). Notably, a recent study demonstrated that different fusogens share similar structural folds, which may provide insight for the discovery of novel fusogens (21).

\section{Cell fusion in physiological processes}

Cell fusion is a widespread physiological phenomenon in several living organisms, from fungi to mammals. Cell fusion participates in various processes, including reproduction, growth and development, and involves complex genetic and molecular mechanisms that remain unclear (2). Previous studies have reported that different differentiated cells may not share the same mechanism in cell fusion, such as having different adhesion or recognition molecules and fusogens $(8,22)$. Molecules involved in some cell fusion phenomena that occur under physiological conditions in mammals are summarized in Table I.

Sperm-oocyte fusion in fertilization is the earliest and most common understanding of cell fusion (23). CD9, expressed on the microvilli of oocytes, and IZUMO1, expressed on sperm, have been demonstrated to play important roles in sperm-oocyte fusion (24). CD9 knockout mice exhibited an abnormal morphology of microvilli in oocytes (25), and CD9 may be associated with cell membrane curvature via interaction with IgSF (24). IZUMO1 forms an adhesion complex by binding to the receptor Juno and mediates the specific recognition of sperm and oocytes during fertilization (26). The IZUMO1-JUNO complex is an essential molecule in cell contact but is not directly involved in plasma membrane merger (27). The fusogens involved in mammalian sperm-egg fusion remain unclear.

The only human fusogen, syncytins, which depend on cell fusion, are present in placental formation (28). Following implantation of the embryo, trophoblast cells differentiate into the inner layer of cytotrophoblasts (CTBs) and the outer layer of syncytiotrophoblasts (STBs) (29). Syncytin-1 is predominantly expressed in STBs (28) and is also present in some tumors (30), myoblasts (31), osteoclasts (32) and oligodendrocytes (33). Syncytin-2 is predominantly expressed in CTBs, and its receptor, major facilitator superfamily domain containing 2 , is present in STBs (34). The function and receptor of syncytin-3 remain unknown.

Macrophages exert physiological functions by forming syncytia under certain conditions, such as osteoclasts that regulate skeletal stability and multinucleated giant cells, which participate in immune responses during infection (35). For macrophages, at least three receptors are essential for cell fusion, including macrophage fusion receptor (MFR), dendritic cell-specific transmembrane protein (DC-STAMP) and CD44 (36). The receptor for MFR is CD47, both of which belong to the immunoglobulin superfamily and are expressed on the macrophage membrane (37). Hyaluronan is considered a ligand for CD44, and CD44 antibodies can inhibit the process of osteoclastogenesis (38). DC-STAMP is an important component of the formation of osteoclasts and multinucleated giant cells (39). The differentiation of myoblasts is a prerequisite for cell fusion, including the expression of adhesion-, migration-, and cytoskeletal rearrangement-associated molecules (40). Recently, in mammals, a new fusogen candidate in myoblasts was discovered, myomaker, which controls the formation of muscle fibers and induces non-fusogenic cells to form multinucleated cells $(41,42)$.

\section{Cell fusion in cancer hallmarks}

Almost 120 years ago, the zoologist, Theodor Boveri, speculated that cancer may originate from the abnormal formation of aneuploidy (43). Cell fusion is an important pathway for aneuploidy formation (3). Currently, the phenomenon of cell fusion in tumors has been gradually recognized, and several fusion cases have been observed in the tumor microenvironment, such as cancer cells fusing with mesenchymal stem cells (MSCs) (44-46), macrophages $(47,48)$, fibroblasts (49) or endothelial cells $(50,51)$. In addition, cumulative reports have demonstrated that cancer cells can obtain hallmarks from cell fusions within the microenvironment (52-54). The reported functions of cell fusions in tumors are summarized in Fig. 2.

Heterogeneity. In addition to genetic or epigenetic alterations in oncogenes or tumor suppressor genes, tumorigenesis is closely associated with chromosomal instability (55). However, previous studies have reported that there are some diploid tumor cells with no obvious mutations at the genetic level, challenging the traditional somatic mutation theory (SMT) $(56,57)$. Aneuploidy is observed in several malignancies, revealing the genetic instability of cancer cells (58). A hypothesis called the heterokaryon-to-synkaryon transition provides an explanation for the heterogeneity of tumors (59), which suggests that the tumor forms a heterokaryon (containing the respective nuclei) and further forms a synkaryon (containing only one nuclei) by rearrangement of the chromosome (60). When homotypic or heterotypic cells fuse, genomic instability caused by chromosomal rearrangement is likely to be fatal (55). Zhou et al (61) also detected DNA double-strand damage and translocation in hybrid cells. Furthermore, Delespaul et al (55) confirmed that hybrids of partly transformed fibroblasts can detect genomic instability and induce hybrid cell tumor formation in mice. Dittmar et al (62) demonstrated that cell fusion in breast cancer, as a mechanism of gene transfer, is involved in the emergence of tumor heterogeneity in evolution. Hybrid progenies overexpress or lose specific genes via chromosome rearrangement, which not only increases tumor heterogeneity but also enhances the ability of cancer cells to adapt to diverse tumor microenvironments (63). Delespaul et al (55) also 


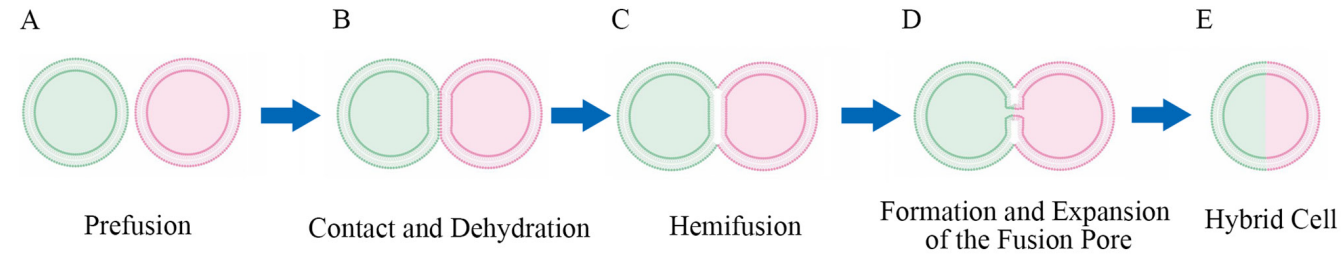

Figure 1. Pattern of cell fusion. (A) Cell pre-fusion state. (B) The membranes of two cells fuse and form a dehydrated zone between the cell membranes. (C) The outer phospholipids of the two cell membranes fuse, which is known as hemifusion. (D) The inner phospholipids of the two cell membranes fuse and form a fusion pore between the two cells. (E) The fusion pore expands and forms a hybrid cell.

demonstrated that tumors formed by fused cells can rapidly promote tumor progression if they have the appropriate genome. However, Su et al reported that cell fusion (such as in breast cancer) can also regulate tumor heterogeneity through epigenetics rather than genetics (64). These phenomena provide a new understanding of the role of cell fusion in heterogeneity, and there are other complex regulatory mechanisms for the formation of tumor heterogeneity.

Oncogenesis. In some cases, genetic instability in aneuploid hybrid cells is likely to trigger the malignant transformation of cells and induce malignant cell behaviors (3). As early as 1992, Munzarova et al (65) observed that advanced melanoma gradually exhibits the biological characteristics of lymphocytes and macrophages, and hypothesized that melanoma may derive from the fusion of host melanocytes and macrophages. Zhou et al (61) reported the fusion of small intestinal epithelial cells (IEC-6 cells) through PEG-informed mice and detected aneuploidy in $40 \%$ of the clones. Some fused cells exhibited transformed phenotypes, such as resistance to apoptosis, enhanced proliferation capacity and chromosomal rearrangement (61). He et al (66) also confirmed that $84.1 \%$ of progeny cells fused with gastric epithelial cells and MSCs were aneuploid and malignant transformation occurred, in the laboratory. However, the association between tumor formation and cell fusion remains unclear. In some studies, hybrid cells have played key roles in suppressing malignant behaviors following cell fusion. For example, in the liver of mice, the fusion of liver tumor cells and stem cells has been demonstrated to suppress tumorigenesis (67). Furthermore, Israel and Schaeffer (68) performed cell fusion between the original cloned normal and transformed liver epithelial cells, and the survival time of hybrid cell transplanted mice was significantly longer. Taken together, these findings confirm the tumor suppressive effect of normal cytoplasm, making the role of cell fusion in tumors more complicated.

Recently, it has been speculated that the SMT cannot explain various tumorigenesis phenomena. Theories that abnormal mitochondria mediate tumorigenesis have been proposed $(69,70)$. Given that the fusion of cytoplasm is involved in the process of cell fusion, the role of mitochondria in cell fusion cannot be ignored (70). According to Seyfried and Shelton (71), the offspring of normal cell nuclei transplanted into the enucleated cytoplasm of tumor cells can still have the characteristics of malignant behavior. This means that metabolic abnormalities caused by cytoplasmic fusion, such as abnormal mitochondrial function, may be the cause of tumors rather than nuclear gene changes (70).
However, malignant transformation of normal cells via cell fusion in vivo, and cell fusion have not been observed in all tumors (72). Similarly, Duelli and Lazebnik have reported that the appearance of fused cells in solid tumors is a rare phenomenon ( 1\%) (73). A hypothesis called the 'dark matter hypothesis' states that because hybrid cells currently identified in tumors mostly rely on the expression of cell surface biomarkers and parental DNA, the instability of progeny cell genes may lead to the inability to continuously express relevant biomarkers (74). In addition, the fusion between tumor cells may be more difficult to detect, resulting in a lower incidence of cell fusion events detected in tumors (74).

Metastasis. Tumor metastasis is a multistep and multistage complex process. Among these multistage processes, epithelial-to-mesenchymal transition (EMT) is a key step (75). EMT is an important adaptive process for tumors to move away from the primary site to distant tissues during tumor metastasis (76). During EMT, the number of adhesion molecules on the surface of tumor cells decreases to express the interstitial phenotype and gain migration capacity (77). Several aggressive cancer cells exhibit metastasis, secretion and phagocytosis, similar to bone marrow-derived cells (BMDCs) (78). One theory is that tumor cells acquire a mesenchymal phenotype derived from the fusion of tumors and BMDCs, such as macrophages (76). Spontaneous fusion of BMDCs with tumor cells in vivo has been observed in both mice (79) and humans (80), and hybrid cells express several genes associated with tumor invasion and metastasis, such as SPARC, MCR1 and MET (76). Recently, Gast et al (48) demonstrated that BMDCs can increase their heterogeneity by fusing with tumors, allowing tumors to acquire a migration phenotype. In addition, macrophage-tumor fusion cells are detected in the peripheral blood of patients with cancer, an observation that is closely associated with the tumor stage and prognosis (48). Furthermore, the tumor-BMDC fusion hypothesis gives tumor metastasis an explanation for the preference of different organs (76). The liver, lungs and bone are usually the preferred metastatic sites for several tumors, and these sites usually have large numbers of BMDCs (81). The migration induced by BMDC-tumor fusion may be more suitable for a new microenvironment (78). In addition to BMDCs, some studies have also demonstrated that MSCs, endothelial cells and fibroblasts can also induce tumor metastasis by spontaneous fusion with cancer cells in the tumor microenvironment (82). Noubissi et al (83) demonstrated that the migratory ability of the nonmetastatic breast cancer cell lines, T47Ds and MCF7s, is significantly enhanced following induction of fusion with 
Table I. Cell fusion related molecules under mammalian physiological conditions.

\begin{tabular}{lllll}
\hline Molecule & \multicolumn{1}{c}{ Expression } & Essential for fusion & Type & Function \\
\hline CD9 & Oocyte microvilli & Yes & Heterotypic & Recognition \\
IZUMO1 & Sperm & Yes & Heterotypic & Recognition \\
Juno & Oocyte & Yes & Heterotypic & Recognition \\
Syncytin-1 & Placenta, myoblast and brain & Yes & Homotypic & Fusogen \\
Syncytin-2 & Placenta & Yes & Homotypic & Fusogen \\
GCM1 & Placenta & Unclear & Homotypic & Regulates syncytins \\
MRF & Macrophage & Yes & Homotypic & Recognition, combine with CD46 \\
CD-STAMP & Macrophage & Yes & Homotypic & Unclear \\
CD44 & Macrophage & No & Homotypic & Recognition \\
CCL2 & Macrophage & Unclear & Homotypic & Regulator \\
ADAM12 & Myoblast & Yes & Homotypic & Adhesion \\
Myomaker & Myoblast & Yes & Homotypic & Unclear \\
FGFRL1 & Myoblast & No & Homotypic & Unclear \\
GRAF1 & Myoblast & Unclear & Homotypic & Regulator \\
\hline
\end{tabular}

MSCs. Similar findings were observed in vascular epithelial cells (84) and tumor-associated fibroblasts (85). In a coculture model of mesenchymal cells and prostate cancer cells by Wang et al (86), spontaneously fused hybrid cells were formed that had the ability to sustain growth, genotype changes and increase malignancy. Conversely, it has been reported that the fusion of mesenchymal cells and tumor cells plays a role in tumor suppression (45). For example, Wei et al (45) demonstrated that FOXF1 can decrease the malignancy of tumors by regulating the fusion of lung cancer cells and MSCs. Thus, the role of cell fusion in tumor progression requires further research and discussion.

Notably, Clawson et al (87) demonstrated that macrophage-tumor cell fusions (MTFs) extracted from the peripheral blood of patients with pancreatic ductal adenocarcinoma (PDAC) have the phenotypes of macrophages, stem cells and PDACs. However, in the orthotopic xenograft tumor model in nude mice, only well-differentiated cell islands were observed in the pancreas, and many disseminated cell populations, such as lungs and liver, were present, but no obvious tumor formation was observed (87). A similar phenomenon has been demonstrated in melanoma (47). For instance, the extracted MTFs did not form transplanted tumors in the subcutaneous area of nude mice but produced metastatic lesions in other organs (47). Collectively, these findings suggest that the fused cells do not directly form tumor metastases, but they form a niche that facilitates tumor metastasis in the tissues they disseminate (88). These seemingly contradictory studies make the theory of tumor fusion cell metastasis controversial.

Drug resistance. The formation of tumor resistance involves several mechanisms, including changes in receptor activity, drug transporters and enzymes that produce inactivated drugs (89). Intercellular gene exchange via cell fusion may potentially cause rapid changes in cancer cell resistance and form subpopulations that are dominant in the microenvironment. Subpopulations of cells with different drug resistance capacities can acquire multidrug resistance through cell fusion (90). Miller et al (91) demonstrated that the 5-fluorouracil-resistant 44FTO cell line spontaneously fuses with the methotrexate-resistant 168FAR cell line to form a double-resistant hybrid cell. Nonresistant tumor cells can also acquire resistance through cell fusion, such as drug-resistant cells formed by tumors and BMDCs (92). Uygur et al (93) recently discovered that in prostate cancer, the fusion of cancer cells with surrounding muscle cells enhances the resistance of tumors. Song et al (94) reported that in hybridization experiments of the oral cancer cell lines, SCC9 and HUVECs, hybrid cells exhibited parental phenotypic characteristics and significantly improved resistance to chemotherapy drugs. Following fusion of melanoma cells with fibroblasts and macrophages, Searles et al (95) observed that functional gene exchange between parental cells produced enhanced resistance in progeny cells. Tumor cells can increase drug resistance by forming polyploid giant cancer cells under the induction of chemotherapy drugs (96). Taken together, these findings suggest that cell fusion can be used as a mechanism to allow cell subpopulations to acquire new or enhanced drug resistance in a complex tumor microenvironment.

Based on the theory that mitochondrial abnormalities cause tumors, the role of cytoplasmic fusion in drug resistance cannot be ignored (70). Due to the hypoxia of the tumor microenvironment and the impaired mitochondrial function of tumor cells, ATP synthesis in several tumor cells occurs mainly through mitochondrial substrate level phosphorylation and glycolysis (97). The switch of metabolic modes will lead to the enhancement of drug resistance. Xu et al (98) demonstrated that cells with mitochondrial defects or hypoxia have an increase in glycolytic activity and drug resistance compared with normal cells. By inhibiting glycolysis, the resistance of tumor cells to the original chemotherapeutic drugs can be overcome (98). Thus, cytoplasmic fusion can provide novel insights into drug resistance from the perspective of metabolism.

Cancer stem cells (CSCs). CSCs are a special subpopulation of tumor cells that play important roles in tumorigenicity, 

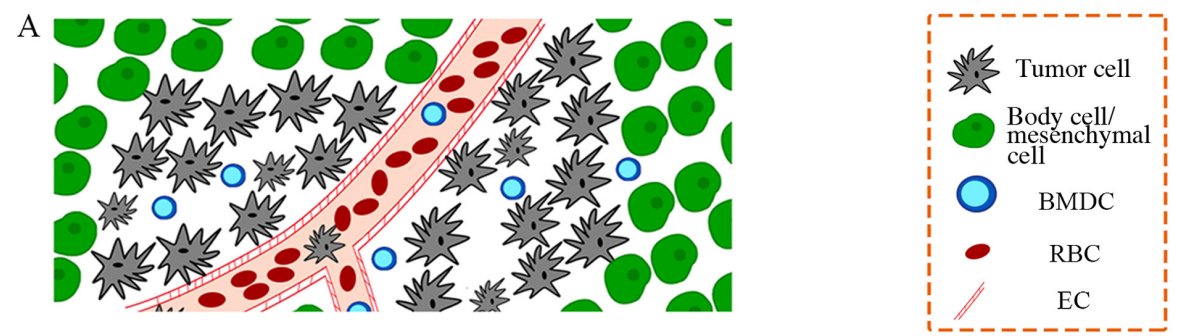

Tumor microenvironment

B

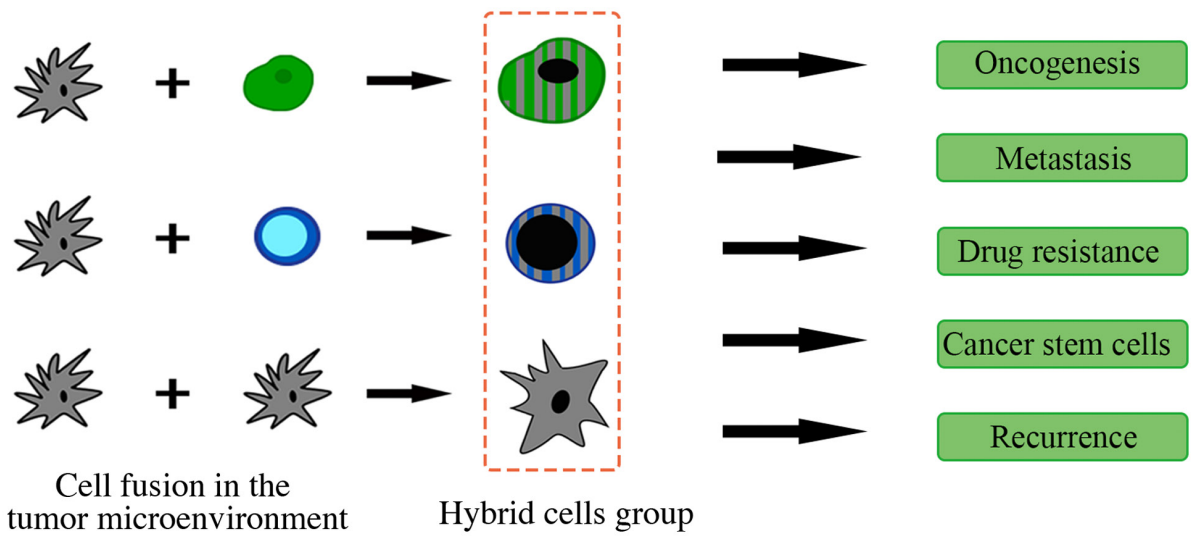

Figure 2. Function of cell fusion in tumor. (A) Simplified tumor microenvironment model. (B) Cancer cells can fuse with other cells, such as mesenchymal cells, BMDCs and cancer cells. The fused hybrid cells increase tumor heterogeneity. These progeny cells enhance the characteristics of oncogenesis, metastasis and drug resistance. Some of the fused hybrid cells exhibit the characteristics of cancer stem cells (GSCs) and cause tumor recurrence. BMDC, bone marrow-derived cell; RBC, red blood cell; EC, endothelial cell.

drug resistance and recurrence (99). CSCs possess several characteristics, such as a low proliferation rate, anti-apoptosis, downregulation of anti-proliferative pathways, drug resistance and a more efficient DNA damage repair capacity, which often make them the source of tumor drug resistance and recurrence (100). There are several hypotheses about the origin of CSCs, one of which is that CSCs are derived from the fusion of stem cells and differentiated cells, as recurrent tumors often exhibit different characteristics and phenotypes compared with the original tumors (101). Wei et al (45) reported that spontaneous fusion can occur in lung cancer and MSCs, and that progenies exhibit a decrease in the proliferation rate and stem cell-like status. Dittmar et al (62) also observed stem cell-like features in hybrid cells fused to breast epithelial cells and breast cancer cells. Similarly, Bartosh et al observed cancer cell cannibalizing MSCs in a 3D coculture model of breast cancer and MSCs. Cancer cells appeared dormant to protect against the hypoxic and undernourished microenvironment (102), which may provide an explanation for tumor recurrence and drug resistance. Under this condition, the hybrid cells enter a state similar to hibernation by decreasing the metabolic level, which cannot be damaged by chemotherapy drugs for an extensive period, and plays a role in the process of tumor recurrence (102). Similarly, Uygur et al (93) demonstrated that under the action of syncytins and AnxA5, the fusion of prostate cancer cells and muscle cells significantly increases the expression of CD133, indicating an increase in tumor stemness. Given the important role of CSCs in tumor recurrence and drug resistance, the specific mechanism of CSCs generated through cell fusion is still worth further investigation.

\section{Targeting cell fusion for tumor treatment}

Cell fusion plays an important role in tumor progression; thus, targeting cell fusion for therapeutic approaches to cancer is also within the scope of this discussion. Currently, research on targeted tumor therapy for the cell fusion process is very scarce; however, there has been some progress in using cell fusion as a tumor therapeutic strategy.

Block cell fusion. Due to the various negative effects of cell fusion in tumors, scientists are naturally driven towards inhibiting cancer heterogeneity, drug resistance, stemness and EMT by blocking cell fusion. Li et al (103) successfully blocked the occurrence and progression of rhabdomyoblastoma in vivo by inhibiting IL-4 receptors (mediating myoblast fusion). The inhibition of cell fusion in some colon cancer models has also yielded positive results (61). However, not all cell fusions in the body are pathological, and scholars have also noted that in some cases of tumor and somatic cell fusion, hybrid cells exhibit more benign phenotypes rather than promoting tumor progression (104). Further understanding of the role of cell fusion in tumors is required, and specific agents that inhibit the cell fusion process of specific tumors are lacking. Reliable inhibitors for cell fusion require further investigation.

Fusogens are an important part of cell fusion, and understanding their function is key to the development of specific cell fusion inhibitors. Fusogens are very complex in composition and function (21). Some loss of functions for fusogens indicate that the lack of fusogens is associated with diseases, such as infertility and muscle dystrophies (18). Defects in 
SNAREs can cause neurocutaneous CEDNIK syndrome and centronuclear myopathy (18). In addition, the structure and function of several fusogens remain unclear, and further research is required.

Immunomodulatory functions. The fusion of BMDCs with tumor cells may be an important mechanism for tumor metastasis and tumor stem cell formation. Due to the immunoregulatory function of BMDCs, some scientists have tried to use hybrids of BMDCs and tumor cells to activate tumor immunity and suppress the progression of tumors $(76,105)$. In the study of Koido et al, the progeny cells fused with tumor cells and dendritic cells (DCs) were used to make cell fusion vaccines to induce anti-tumor specific immunity. This vaccine utilizes DCs to expose entire tumor-associated antigens, and present antigens to activate CD8+ and CD4+ T cells $(106,107)$. Previous studies have reported that newly fused hybrid cells are prone to necrosis, and release a large number of proteins locally (108), which may also be presented by DCs as tumor antigens to activate the immune system (72).

Some new biomaterial technologies have also been incorporated into the idea of cell fusion-targeted tumor therapy. Recently, Liu et al (109) tried to construct immunotherapeutic nanoplatforms from hybrid cell membranes derived from cancer cells and DCs to achieve more efficient and precise photodynamic therapy (PDT). Utilizing DC-tumor hybrid cell membranes for tumor tropism successfully enriches PDT nanomaterials to tumor entities (109). This tumor-specific immunotherapy method expands the method of cell fusion for tumor treatment.

Cell fusion in radiotherapy. Radiotherapy is a common method used to treat malignancies, and radiation is also an important inducer of cell fusion (110). Thus, the phenomenon of cell fusion during radiotherapy is worthy of discussion. Rizvi et al (111) reported that gamma-ray radiation can induce the fusion of small intestinal stem cells and BMDCs, and this effect is significantly increased in small intestine tumors. Further research in the BMDC-transplanted mouse model demonstrated that the proliferation of epithelial cells increased significantly following radiation, which was associated with the increase in fusion of BMDCs and the small intestinal epithelium (111). And as the radiation dose increases, the number of fused cells also increases (112). Garvin et al (113) reported that CD163 (macrophage phenotype)-positive tumor cells were detected in some patients with breast cancer undergoing breast-conserving surgery and radiotherapy. The increase in CD163-positive cancer cells is associated with the infiltration of macrophages in the tumor stroma, which may be due to radiation-induced macrophage-tumor fusion. These CD163-positive cells have strong resistance to radiotherapy, and indicate a poor prognosis (113). The spontaneous fusion hybrid of MCF-7 cells and macrophages in vitro and in vivo confirmed its radioresistance and DNA repair abilities, which makes the treatment of tumors more difficult (114). In addition, Yeh et al (115) demonstrated that the fusion of macrophages and small intestinal stromal cells caused by radiation can increase chronic fibrosis of the intestinal stroma. Collectively, these findings suggest that it is important to consider the influence of radiation on tumor cell fusion when undergoing radiotherapy.

Diagnosis and prognosis. The increase in tumor heterogeneity caused by cell fusion is closely associated with the grade and prognosis of the tumor. The degree of tumor malignancy and prognosis can be determined by detecting the frequency of tumor cell fusion (48). Gast et al (48) successfully constructed hybrid cells of macrophages and tumor cells in vitro and detected tumor hybrid cells in circulating blood in mice. The number of hybrid cells in peripheral blood was significantly associated with the tumor stage and survival of mice (48). This suggests that hybrid cells may also be detected in human peripheral blood and used as a diagnostic tool to determine the cancer stage and patient prognosis. However, several details about the mechanism of cell fusion in tumors are yet to be investigated, and thus, there is no effective way to prevent tumor cell fusion. Furthermore, the direct application of hybrid cells to treat tumors requires full verification of the safety of the progeny (116).

\section{Conclusions}

Cell fusion is essential for the normal growth and development of organisms, but the consequences of unexpected cell fusion may also be catastrophic, such as initiating cancer. Although the theory that cancer originates from cell fusion has been proposed for a century, in recent decades, the existence of spontaneous cell fusion in human tumors has been confirmed. Currently, the effects on cell fusion in tumors are focused on the following aspects: i) Whether hybrid cells can cause tumor formation; ii) which cells can hybridize with tumor cells; iii) how to detect hybrid cells in tumors; iv) the association between cell fusion and tumor progression; v) the role of cytoplasm in tumor fusion and vi) the clinical value of hybrid cells in tumors $(3,8,61,72,74)$. According to the SMT, offspring genome changes via cell fusion cause cells to acquire new phenotypes and biological characteristics. This directly triggers further cell invasion, metastasis, drug resistance and recurrence (57). In addition, given that cell genetic abnormalities do not exist in all tumor cells, changes via cytoplasmic fusion, particularly mitochondrial abnormalities, can also induce malignant characteristics (69). Metabolic disorders caused by cell fusion are also an important driving force for the progression of cancer cells (97). Recently, some targeting cell fusion treatment methods have gradually been proposed. However, due to the large heterogeneity of cell fusion in different tumors, these treatment options are unstable and cannot be applied for short-term use $(106,107,109,116)$. Cell fusion is widespread in the tumor microenvironment. Based on the limited understanding of tumor cell fusion, its scientific value is worthy of further investigation.

\section{Acknowledgements}

Not applicable.

\section{Funding}

The present review was partly supported by a grant from the National Natural Science Foundation of China (grant no. 81572488 , to WX). 


\section{Availability of data and materials}

Not applicable.

\section{Authors' contributions}

HFW and WX collected most of the data and drafted the initial manuscript. BZX, YHW, and DYY interpreted the data. HYZ and XBJ made critical revisions to the article. PF supervised all of the research work and gave the final approval for the publication of this article. Data authentication is not applicable.

\section{Ethics approval and consent to participate}

Not applicable.

\section{Patient consent for publication}

Not applicable.

\section{Competing interests}

The authors declare that they have no competing interests.

\section{References}

1. Brukman NG, Uygur B, Podbilewicz B and Chernomordik LV: How cells fuse. J Cell Biol 218: 1436-1451, 2019.

2. Oren-Suissa M and Podbilewicz B: Cell fusion during development. Trends Cell Biol 17: 537-546, 2007.

3. Bastida-Ruiz D, Van Hoesen K and Cohen M: The dark side of cell fusion. Int J Mol Sci 17: 638, 2016.

4. Ku JWK, Chen Y, Lim BJW, Gasser S, Crasta KC and Gan YH: Bacterial-induced cell fusion is a danger signal triggering cGAS-STING pathway via micronuclei formation. Proc Nat Acad Sci USA 117: 15923-15934, 2020.

5. Laberge GS, Duvall E, Haedicke K and Pawelek J: Leukocyte-cancer cell fusion-genesis of a deadly journey. Cells 8: 170, 2019.

6. Willkomm L and Bloch W: State of the art in cell-cell fusion. Methods Mol Biol 1313: 1-19, 2015.

7. Zito F, Lampiasi N, Kireev I and Russo R: United we stand: Adhesion and molecular mechanisms driving cell fusion across species. Eur J Cell Biol 95: 552-562, 2016.

8. Hernández JM and Podbilewicz B: The hallmarks of cell-cell fusion. Development 144: 4481-4495, 2017.

9. Raj I, Sadat Al Hosseini H, Dioguardi E, Nishimura K, Han L, Villa A, de Sanctis D and Jovine L: Structural basis of egg coat-sperm recognition at fertilization. Cell 169: 1315-1326. e17, 2017.

10. Li Y, Augustine GJ and Weninger K: Kinetics of complexin binding to the SNARE complex: Correcting single molecule FRET measurements for hidden events. Biophys J 93 2178-2187, 2007.

11. Donaldson SH Jr, Lee CT Jr, Chmelka BF and Israelachvili JN: General hydrophobic interaction potential for surfactant/lipid bilayers from direct force measurements between light-modulated bilayers. Proc Natl Acad Sci USA 108: 15699-15704, 2011.

12. Chernomordik LV, Kozlov MM, Lě̌kin SL, Markin VS and Chizmadzhaev IuA: Membrane fusion: Local interactions and structural rearrangements. Dokl Akad Nauk SSSR 288: 1009-1013, 1986 (In Russian).

13. Chernomordik LV and Kozlov MM: Membrane hemifusion: Crossing a chasm in two leaps. Cell 123: 375-382, 2005.

14. Skehel JJ and Wiley DC: Receptor binding and membrane fusion in virus entry: The influenza hemagglutinin. Annu Rev Biochem 69: 531-569, 2000.

15. Eckert DM and Kim PS: Mechanisms of viral membrane fusion and its inhibition. Annu Rev Biochem 70: 777-810, 2001.
16. Weber T, Zemelman BV, McNew JA, Westermann B, Gmachl M, Parlati F, Söllner TH and Rothman JE: SNAREpins: Minimal machinery for membrane fusion. Cell 92: 759-772, 1998.

17. Calder LJ and Rosenthal PB: Cryomicroscopy provides structural snapshots of influenza virus membrane fusion. Nat Struct Mol Biol 23: 853-858, 2016.

18. Segev N, Avinoam O and Podbilewicz B: Fusogens. Curr Biol 28 R378-R380, 2018.

19. Mercapide J, Rappa G and Lorico A: The intrinsic fusogenicity of glioma cells as a factor of transformation and progression in the tumor microenvironment. Int J Cancer 131: 334-343, 2012.

20. Esnault C, Priet S, Ribet D, Vernochet C, Bruls T, Lavialle C, Weissenbach $\mathrm{J}$ and Heidmann T: A placenta-specific receptor for the fusogenic, endogenous retrovirus-derived, human syncytin-2. Proc Natl Acad Sci USA 105: 17532-17537, 2008.

21. Fédry J, Liu Y, Péhau-Arnaudet G, Pei J, Li W, Tortorici MA, Traincard F, Meola A, Bricogne G, Grishin NV, et al: The ancient gamete fusogen HAP2 is a eukaryotic class II fusion protein. Cell 168: 904-915.e10, 2017

22. Aguilar PS, Baylies MK, Fleissner A, Helming L, Inoue N, Podbilewicz B, Wang H and Wong M: Genetic basis of cell-cell fusion mechanisms. Trends Genet 29: 427-437, 2013.

23. Okabe M: Sperm-egg interaction and fertilization: Past, present, and future. Biol Reprod 99: 134-146, 2018.

24. Primakoff $P$ and Myles DG: Cell-cell membrane fusion during mammalian fertilization. FEBS Lett 581: 2174-2180, 2007.

25. Runge KE, Evans JE, He ZY, Gupta S, McDonald KL, Stahlberg H, Primakoff P and Myles DG: Oocyte CD9 is enriched on the microvillar membrane and required for normal microvillar shape and distribution. Dev Biol 304: 317-325, 2007.

26. Aydin H, Sultana A, Li S, Thavalingam A and Lee JE: Molecular architecture of the human sperm IZUMO1 and egg JUNO fertilization complex. Nature 534: 562-565, 2016.

27. Ohto U, Ishida $\mathrm{H}$, Krayukhina $\mathrm{E}$, Uchiyama $\mathrm{S}$, Inoue $\mathrm{N}$ and Shimizu T: Structure of IZUMO1-JUNO reveals sperm-oocyte recognition during mammalian fertilization. Nature 534: 566-569, 2016

28. Mi S, Lee X, Li X, Veldman GM, Finnerty H, Racie L, LaVallie E, Tang XY, Edouard P, Howes S, et al: Syncytin is a captive retroviral envelope protein involved in human placental morphogenesis. Nature 403: 785-789, 2000

29. Gude NM, Roberts CT, Kalionis B and King RG: Growth and function of the normal human placenta. Thromb Res 114: 397-407, 2004

30. Bjerregaard B, Holck S, Christensen IJ and Larsson LI: Syncytin is involved in breast cancer-endothelial cell fusions. Cell Mol Life Sci 63: 1906-1911, 2006.

31. Bjerregard B, Ziomkiewicz I, Schulz A and Larsson LI Syncytin-1 in differentiating human myoblasts: Relationship to caveolin-3 and myogenin. Cell Tissue Res 357: 355-362, 2014.

32. Søe K, Andersen TL, Hobolt-Pedersen AS, Bjerregaard B, Larsson LI and Delaisse JM: Involvement of human endogenous retroviral syncytin-1 in human osteoclast fusion. Bone 48 837-846, 2011

33. Antony JM, van Marle G, Opii W, Butterfield DA, Mallet F, Yong VW, Wallace JL, Deacon RM, Warren K and Power C: Human endogenous retrovirus glycoprotein-mediated induction of redox reactants causes oligodendrocyte death and demyelination. Nat Neurosci 7: 1088-1095, 2004.

34. Dupressoir A, Vernochet C, Bawa O, Harper F, Pierron G, Opolon P and Heidmann T: Syncytin-A knockout mice demonstrate the critical role in placentation of a fusogenic, endogenous retrovirus-derived, envelope gene. Proc Natl Acad Sci USA 106: 12127-12132, 2009.

35. Vignery A: Macrophage fusion: The making of osteoclasts and giant cells. J Exp Med 202: 337-340, 2005.

36. Helming L and Gordon S: Molecular mediators of macrophage fusion. Trends Cell Biol 19: 514-522, 2009.

37. Saginario C, Sterling H, Beckers C, Kobayashi R, Solimena M, Ullu E and Vignery A: MFR, a putative receptor mediating the fusion of macrophages. Mol Cell Biol 18: 6213-6223, 1998.

38. Kania JR, KehatStadler T and Kupfer SR: CD44 antibodies inhibit osteoclast formation. J Bone Miner Res 12: 1155-1164, 1997.

39. Yagi M, Miyamoto $T$, Toyama $Y$ and Suda $T$ : Role of DC-STAMP in cellular fusion of osteoclasts and macrophage giant cells. J Bone Miner Metab 24: 355-358, 2006

40. Horsley V and Pavlath GK: Forming a multinucleated cell: Molecules that regulate myoblast fusion. Cells Tissues Organs 176: 67-78, 2004. 
41. Quinn ME, Goh Q, Kurosaka M, Gamage DG, Petrany MJ, Prasad V and Millay DP: Myomerger induces fusion of non-fusogenic cells and is required for skeletal muscle development. Nat Commun 8: 15665, 2017.

42. Mitani Y, Vagnozzi RJ and Millay DP: In vivo myomaker-mediated heterologous fusion and nuclear reprogramming. FASEB J 31: 400-411, 2017.

43. Boveri T: Concerning the origin of malignant tumours by Theodor Boveri. Translated and annotated by Henry Harris J Cell Sci 121 (Suppl 1): S1-S84, 2008.

44. Sun C, Zhao D, Dai X, Chen J, Rong X, Wang H, Wang A, Li M, Dong J, Huang Q and Lan Q: Fusion of cancer stem cells and mesenchymal stem cells contributes to glioma neovascularization. Oncol Rep 34: 2022-2030, 2015.

45. Wei HJ, Nickoloff JA, Chen WH, Liu HY, Lo WC, Chang YT, Yang PC, Wu CW, Williams DF, Gelovani JG and Deng WP: FOXF1 mediates mesenchymal stem cell fusion-induced reprogramming of lung cancer cells. Oncotarget 5: 9514-9529, 2014.

46. Melzer C, von der Ohe $\mathrm{J}$ and Hass R: In vitro fusion of normal and neoplastic breast epithelial cells with human mesenchymal stroma/stem cells partially involves tumor necrosis factor receptor signaling. Stem Cells 36: 977-989, 2018

47. Clawson GA, Matters GL, Xin P, Imamura-Kawasawa $\mathrm{Y}$, Du Z, Thiboutot DM, Helm KF, Neves RI and Abraham T: Macrophage-tumor cell fusions from peripheral blood of melanoma patients. PLoS One 10: e0134320, 2015.

48. Gast CE, Silk AD, Zarour L, Riegler L, Burkhart JG, Gustafson KT, Parappilly MS, Roh-Johnson M, Goodman JR Olson B, et al: Cell fusion potentiates tumor heterogeneity and reveals circulating hybrid cells that correlate with stage and survival. Sci Adv 4: eaat7828, 2018

49. Yu L, Guo W, Zhao S, Wang F and Xu Y: Fusion between cancer cells and myofibroblasts is involved in osteosarcoma. Onco Lett 2: 1083-1087, 2011

50. Powell AE, Anderson EC, Davies PS, Silk AD, Pelz C, Impey S and Wong MH: Fusion between intestinal epithelial cells and macrophages in a cancer context results in nuclear reprogramming. Cancer Res 71: 1497-1505, 2011.

51. Huang CM, Yan TL, Xu Z, Wang M, Zhou XC, Jiang EH Liu K, Shao Z and Shang ZJ: Hypoxia enhances fusion of oral squamous carcinoma cells and epithelial cells partly via the epithelial-mesenchymal transition of epithelial cells. Biomed Res Int 2018: 5015203, 2018.

52. Lu X and Kang Y: Cell fusion as a hidden force in tumor progression. Cancer Res 69: 8536-8539, 2009.

53. Yin L, Hu P, Shi X, Qian W, Zhau HE, Pandol SJ, Lewis MS, Chung LWK and Wang R: Cancer cell's neuroendocrine feature can be acquired through cell-cell fusion during cancer-neural stem cell interaction. Sci Rep 10: 1216, 2020.

54. Dörnen J, Myklebost O and Dittmar T: Cell fusion of mesenchymal stem/stromal cells and breast cancer cells leads to the formation of hybrid cells exhibiting diverse and individual (stem cell) characteristics. Int J Mol Sci 21: 9636, 2020.

55. Delespaul L, Merle C,Lesluyes T,Lagarde P,Le Guellec S, Pérot G, Baud J, Carlotti M, Danet C, Fèvre M, et al: Fusion-mediated chromosomal instability promotes aneuploidy patterns that resemble human tumors. Oncogene 38: 6083-6094, 2019.

56. Hedley DW, Leary JA and Kirsten F: Metastatic adenocarcinoma of unknown primary site: Abnormalities of cellular DNA content and survival. Eur J Cancer Clin Oncol 21: 185-189, 1985.

57. Baker SG: A cancer theory kerfuffle can lead to new lines of research. J Natl Cancer Inst 107: dju405, 2014.

58. Mertens F, Johansson B,Höglund M and Mitelman F: Chromosomal imbalance maps of malignant solid tumors: A cytogenetic survey of 3185 neoplasms. Cancer Res 57: 2765-2780, 1997.

59. Bjerkvig R, Tysnes BB, Aboody KS, Najbauer J and Terzis AJ: Opinion: The origin of the cancer stem cell: Current controversies and new insights. Nat Rev Cancer 5: 899-904, 2005.

60. Mohr M, Zaenker KS and Dittmar T: Fusion in cancer: An explanatory model for aneuploidy, metastasis formation, and drug resistance. Methods Mol Biol 1313: 21-40, 2015

61. Zhou X, Merchak K, Lee W, Grande JP, Cascalho M and Platt JL: Cell fusion connects oncogenesis with tumor evolution. Am J Pathol 185: 2049-2060, 2015.

62. Dittmar T, Schwitalla S, Seidel J, Haverkampf S, Reith G, Meyer-Staeckling S, Brandt BH, Niggemann B and Zänker KS Characterization of hybrid cells derived from spontaneous fusion events between breast epithelial cells exhibiting stem-like characteristics and breast cancer cells. Clin Exp Metastas 28: 75-90, 2011
63. Goldenberg DM, Rooney RJ, Loo M, Liu D and Chang CH: In-vivo fusion of human cancer and hamster stromal cells permanently transduces and transcribes human DNA. PLoS One 9: e107927, 2014

64. Su Y, Subedee A, Bloushtain-Qimron N, Savova V, Krzystanek M, Li L, Marusyk A, Tabassum DP, Zak A, Flacker MJ, et al: Somatic cell fusions reveal extensive heterogeneity in basal-like breast cancer. Cell Rep 11: 1549-1563, 2015.

65. Munzarova M, Lauerova L and Capkova J: Are advanced malignant melanoma cells hybrids between melanocytes and macrophages? Melanoma Res 2: 127-129, 1992.

66. He X, Li B, Shao Y, Zhao N, Hsu Y, Zhang Z and Zhu L: Cell fusion between gastric epithelial cells and mesenchymal stem cells results in epithelial-to-mesenchymal transition and malignant transformation. BMC Cancer 15: 24, 2015.

67. Faggioli F, Sacco MG, Susani L, Montagna C and Vezzoni P: Cell fusion is a physiological process in mouse liver. Hepatology 48: 1655-1664, 2008

68. Israel BA and Schaeffer WI: Cytoplasmic suppression of malignancy. In Vitro Cell Dev Biol 23: 627-632, 1987.

69. Seyfried TN: Cancer as a mitochondrial metabolic disease. Front Cell Dev Biol 3: 43, 2015.

70. Hsu CC, Tseng LM and Lee HC: Role of mitochondrial dysfunction in cancer progression. Exp Biol Med (Maywood) 241: 1281-1295, 2016.

71. Seyfried TN and Shelton LM: Cancer as a metabolic disease Nutr Metab (Lond) 7: 7, 2010

72. Platt JL, Zhou X, Lefferts AR and Cascalho M: Cell fusion in the war on cancer: A perspective on the inception of malignancy. Int J Mol Sci 17: 1118, 2016

73. Duelli D and Lazebnik Y: Cell fusion: A hidden enemy? Cancer Cell 3: 445-448, 2003

74. Weiler J and Dittmar T: Cell fusion in human cancer: The dark matter hypothesis. Cells 8: 132, 2019.

75. Mittal V: Epithelial mesenchymal transition in tumor metastasis. Annu Rev Pathol 13: 395-412, 2018

76. Pawelek JM and Chakraborty AK: Fusion of tumour cells with bone marrow-derived cells: A unifying explanation for metastasis. Nat Rev Cancer 8: 377-386, 2008.

77. Kalluri R and Neilson EG: Epithelial-mesenchymal transition and its implications for fibrosis. J Clin Invest 112: 1776-1784, 2003.

78. Seyfried TN and Huysentruyt LC: On the origin of cancer metastasis. Crit Rev Oncog 18: 43-73, 2013.

79. Chakraborty AK, Sodi S, Rachkovsky M, Kolesnikova N, Platt JT, Bolognia JL and Pawelek JM: A spontaneous murine melanoma lung metastasis comprised of host $\mathrm{x}$ tumor hybrids. Cancer Res 60: 2512-2519, 2000.

80. Yilmaz Y, Lazova R, Qumsiyeh M, Cooper D and Pawelek J: Donor $Y$ chromosome in renal carcinoma cells of a female BMT recipient: Visualization of putative BMT-tumor hybrids by FISH. Bone Marrow Transplant 35: 1021-1024, 2005.

81. Fidler IJ: Timeline: The pathogenesis of cancer metastasis: The 'seed and soil' hypothesis revisited. Nat Rev Cancer 3: 453-458, 2003.

82. Jiang E, Yan T, Xu Z and Shang Z: Tumor microenvironment and cell fusion. Biomed Res Int 2019: 5013592, 2019.

83. Noubissi FK, Harkness T, Alexander CM and Ogle BM: Apoptosis-induced cancer cell fusion: A mechanism of breast cancer metastasis. FASEB J 29: 4036-4045, 2015.

84. Choi $\mathrm{H}$ and Moon A: Crosstalk between cancer cells and endothelial cells: Implications for tumor progression and intervention. Arch Pharm Res 41: 711-724, 2018.

85. Kalluri R: The biology and function of fibroblasts in cancer. Nat Rev Cancer 16: 582-598, 2016.

86. Wang R, Sun X, Wang CY, Hu P, Chu CY, Liu S, Zhau HE and Chung LW: Spontaneous cancer-stromal cell fusion as a mechanism of prostate cancer androgen-independent progression. PLoS One 7: e42653, 2012.

87. Clawson GA, Matters GL, Xin P, McGovern C, Wafula E, dePamphilis C, Meckley M, Wong J, Stewart L, D'Jamoos C, et al: 'Stealth dissemination' of macrophage-tumor cell fusions cultured from blood of patients with pancreatic ductal adenocarcinoma. PLoS One 12: e0184451, 2017.

88. Clawson G: The fate of fusions. Cells 8: 13, 2018

89. Kachalaki S, Ebrahimi M, Mohamed Khosroshahi L, Mohammadinejad S and Baradaran B: Cancer chemoresistance; biochemical and molecular aspects: A brief overview. Eur J Pharm Sci 89: 20-30, 2016

90. Vasan N, Baselga J and Hyman DM: A view on drug resistance in cancer. Nature 575: 299-309, 2019. 
91. Miller FR, Mohamed AN and McEachern D: Production of a more aggressive tumor cell variant by spontaneous fusion of two mouse tumor subpopulations. Cancer Res 49: 4316-4321, 1989.

92. Nagler C, Hardt C, Zanker KS and Dittmar T: Co-cultivation of murine BMDCs with 67NR mouse mammary carcinoma cells give rise to highly drug resistant cells. Cancer Cell Int 11: 21, 2011.

93. Uygur B, Leikina E, Melikov K, Villasmil R, Verma SK, Vary CPH and Chernomordik LV: Interactions with muscle cells boost fusion, stemness, and drug resistance of prostate cancer cells. Mol Cancer Res 17: 806-820, 2019.

94. Song K, Song Y, Zhao XP, Shen H, Wang M, Yan TL, Liu K and Shang ZJ: Oral cancer/endothelial cell fusion experiences nuclear fusion and acquisition of enhanced survival potential. Exp Cell Res 328: 156-163, 2014.

95. Searles SC, Santosa EK and Bui JD: Cell-cell fusion as a mechanism of DNA exchange in cancer. Oncotarget 9: 6156-6173, 2017

96. Mirzayans R and Murray D: Intratumor heterogeneity and therapy resistance: Contributions of dormancy, apoptosis reversal (Anastasis) and cell fusion to disease recurrence. Int J Mol Sci 21: 1308, 2020.

97. Seyfried TN, Arismendi-Morillo G, Mukherjee P and Chinopoulos C: On the origin of ATP synthesis in cancer. iScience 23: 101761, 2020

98. Xu RH, Pelicano H, Zhou Y, Carew JS, Feng L, Bhalla KN, Keating MJ and Huang P: Inhibition of glycolysis in cancer cells: A novel strategy to overcome drug resistance associated with mitochondrial respiratory defect and hypoxia. Cancer Res 65: 613-621, 2005.

99. Beck B and Blanpain C: Unravelling cancer stem cell potential Nat Rev Cancer 13: 727-738, 2013.

100. Batlle E and Clevers H: Cancer stem cells revisited. Nat Med 23 1124-1134, 2017.

101. Dittmar T, Nagler C, Schwitalla S, Reith G, Niggemann B and Zänker KS: Recurrence cancer stem cells-made by cell fusion? Med Hypotheses 73: 542-547, 2009.

102. Bartosh TJ, Ullah M, Zeitouni S, Beaver J and Prockop DJ: Cancer cells enter dormancy after cannibalizing mesenchymal stem/stromal cells (MSCs). Proc Natl Acad Sci USA 113 E6447-E6456, 2016.

103. Li G, Kikuchi K, Radka M, Abraham J, Rubin BP and Keller C: IL-4 receptor blockade abrogates satellite cell Rhabdomyosarcoma fusion and prevents tumor establishment. Stem Cells 31: 2304-2312, 2013.

104. Platt JL and Cascalho M: Cell fusion in malignancy: A cause or consequence? a provocateur or cure? Cells 8: 587, 2019.
105. Fais S and Overholtzer M: Cell-in-cell phenomena in cancer. Nat Rev Cancer 18: 758-766, 2018.

106. Koido S, Homma S, Okamoto M, Namiki Y, Takakura K, Uchiyama K, Kajihara M, Arihiro S, Imazu H, Arakawa H, et al: Fusions between dendritic cells and whole tumor cells as anticancer vaccines. Oncoimmunology 2: e24437, 2013.

107. Koido S: Dendritic-tumor fusion cell-based cancer vaccines. Int J Mol Sci 17: 828, 2016.

108. Platt JL and Cascalho M: IgM in the kidney: A multiple personality disorder. Kidney Int 88: 439-441, 2015.

109. Liu WL, Zou MZ, Liu T, Zeng JY, Li X, Yu WY, Li CX, Ye JJ, Song W, Feng J and Zhang XZ: Expandable immunotherapeutic nanoplatforms engineered from cytomembranes of hybrid cells derived from cancer and dendritic cells. Adv Mater 31: e1900499, 2019

110. Hass R, von der Ohe $\mathrm{J}$ and Ungefroren $\mathrm{H}$ : Potential role of MSC/cancer cell fusion and EMT for breast cancer stem cell formation. Cancers (Basel) 11: 1432, 2019.

111. Rizvi AZ, Swain JR, Davies PS, Bailey AS, Decker AD, Willenbring $\mathrm{H}$, Grompe M, Fleming WH and Wong MH: Bone marrow-derived cells fuse with normal and transformed intestinal stem cells. Proc Natl Acad Sci USA 103: 6321-6325, 2006.

112. Davies PS, Powell AE, Swain JR and Wong MH: Inflammation and proliferation act together to mediate intestinal cell fusion. PLoS One 4: e6530, 2009.

113. Garvin S, Oda H, Arnesson LG, Lindström A and Shabo I: Tumor cell expression of CD163 is associated to postoperative radiotherapy and poor prognosis in patients with breast cancer treated with breast-conserving surgery. J Cancer Res Clin Oncol 144: 1253-1263, 2018

114. Lindström A, Midtbö K, Arnesson LG, Garvin S and Shabo I: Fusion between M2-macrophages and cancer cells results in a subpopulation of radioresistant cells with enhanced DNA-repair capacity. Oncotarget 8: 51370-51386, 2017.

115. Yeh MH, Chang YH, Tsai YC, Chen SL, Huang TS, Chiu JF and Ch'ang $\mathrm{HJ}$ : Bone marrow derived macrophages fuse with intestine stromal cells and contribute to chronic fibrosis after radiation. Radiother Oncol 119: 250-258, 2016.

116. Willenbring H: Therapeutic cell fusion. Br J Surg 92: 923-924, 2005 .

This work is licensed under a Creative Commons Attribution-NonCommercial-NoDerivatives 4.0 International (CC BY-NC-ND 4.0) License. 